\title{
Kosti: jedna od najranijih sekundarnih sirovina
}

Selena Vitezović

DOI: $10.17234 / 9789531757232-03$

Uvod

Recikliranje i ponovna uporaba raznih materijala i predmeta javljaju se kroz cijelu ljudsku povijest, još od samih početaka (Amick 2015). Međutim, odnos prema praksi recikliranja dosta se mijenjao tijekom vremena i u različitim kulturama. U novije vrijeme recikliranje i ponovna uporaba prošli su kroz nagle i drastične promjene, prvo s industrijskom revolucijom, naglim povećanjem proizvodnje i stvaranjem „potrošačkog društva”, a potom, posljednjih desetljeća, s rastućom svijesti o neophodnosti zaštite okoliša i održivosti resursa (Cooper 2008; Amick 2015: 4-5).

Recikliranje i ponovna uporaba često se vezuju za nedostatak i štednju (vremena, truda, materijala itd.), osobito iz današnje perspektive, gdje se prikupljanjem sekundarnih sirovina najčešće bave najsiromašniji slojevi društva ili ekonomski vrlo siromašne zemlje. I arheološki dokumentirani primjeri ponovne uporabe često se interpretiraju kroz prizmu današnjeg pogleda, odnosno kao odraz štednje i ekonomske isplativosti. Razlozi i motivi za recikliranje u različitim kulturama, međutim, nisu bili samo ekonomski, već i kulturni, odražavajući kulturni odnos prema određenim predmetima i sirovinama od kojih su nastali (cf. Drackner 2005; Amick 2015).

Arheološki primjeri reciklaže i ponovne uporabe u različitim društvima brojni su i raznovrsni. Najuočljiviji su primjeri koji se odnose na sekundarno korištenje građevinskog materijala (Barker 2010; 2015), kao i u slučajevima takozvanih transformativnih tehnologija, točnije metalurgije, prerade stakla i drugih (Grünewald \& Hartmann 2015; Al-Bashaireh et al. 2016).

Načini ponovne uporabe i recikliranja mogu se razvrstati u nekoliko grupa. Tako Michael Schiffer (Schiffer 2010: 32 ff.) razlikuje kruženje predmeta, recikliranje, sekundarnu uporabu i procese konzerviranja (lateral cylcing, recycling, secondary use, conservatory processes), odnosno promjenu korisnika nekog predmeta, iskorištavanje nekog predmeta za izradu novog, promjenu namjene, ali ne i oblika nekog predmeta, i konzerviranje, odnosno čuvanje predmeta tijekom dužeg vremena. Daniel Amick koristi koncepte uporabe, ponovne uporabe, recikliranja, promjene u volumenu i čak strvinarenja, odnosno prikupljanja otpada (use, re-use, recycling, re-sizing, scavenging) (Amick 2014).

U slučajevima ekstraktivno-reduktivnih tehnologija reciklažu i ponovnu uporabu nije uvijek moguće raspoznati u arheološkom materijalu. Ipak, među najranijim primjerima jesu slučajevi sekundarne uporabe litičkih artefakata, takozvani primjeri „dvostruke patine” (double patina), kada se artefakt koji je već u arheološkom sloju ponovno preradi i iskoristi (Amick 2015: 5-6). Takvi su slučajevi zabilježeni još u donjem paleolitiku, na lokalitetima kao što su Fuente Nueva 3 u Španjolskoj (Toro-Moyano et al. 2009), Qesem pećina u Izraelu (Gopher et al. 2005; Barkai et al. 2009) i drugi (Amick 2015: 6). 
Osobito specifični materijali u smislu uporabe i ponovne uporabe jesu koštani materijali. Koštane sirovine u širem smislu obuhvaćaju sve tvrde sirovine životinjskog porijekla (animal hard tissue), točnije, tu pripadaju kosti, rogovi cervida, zubi, uključujući i bjelokost, ljušture mekušaca pa čak i ljuske jaja, oklop kornjača i materijali kertinastog sastava kao što su rogovi bovida (Averbouh 2000: 187; Christensen 2004).

Izvorno se kosti i zubi mogu nabaviti od životinja ubijenih za prehranu ili od pronađenih trupla životinja, dok se rogovi i ljušture mekušaca mogu dobiti kako lovom, tako i prikupljanjem. Naime, cervidi (jelen, irvas, srndać itd.) odbacuju svoje rogove jednom godišnje, koji se potom mogu razmjerno lako pokupiti, s obzirom na to da se često odbacuju na istom mjestu (CluttonBrock 1984; Reitz \& Wing 2008). Ljušture mekušaca, također se, pored onih iskorištenih u prehrani, bez poteškoća mogu prikupiti na obali rijeke ili mora, ili se čak mogu prikupiti fosilni. Radi se, dakle, o sirovinama koje su, praktički, kuhinjski otpad, ili prikupljen neživi dio nekog organizma, također odbačen ili nepotreban, tako da je već sama njihova uporaba jedan vid recikliranja. Koštane sirovine stoga se mogu smatrati i jednim od najranijih primjera ponovne uporabe i korištenja otpadnog materijala. S jedne strane dostupnost, a s druge fizičko-kemijska i mehanička svojstva ovih materijala čine ih jako pogodnim za izradu širokog repertoara predmeta (MacGregor 1985; Christensen 2004): za razna oruđa, oružje, pomoćne predmete, dijelove kompozitnog oruđa, ali i za ukrase pa čak i za umjetničke predmete (Kokabi et al. eds. 1996; Schibler 2007) i druge svrhe kao građevinski materijal, gorivo i drugo (Vitezović 2016a).

\section{Paleolitik}

Koštane se sirovine javljaju vrlo rano u prapovijesti. Prvi podaci o njihovu korištenju potječu iz donjega paleolitika. Najstarije upotrijebljene koštane sirovine jesu odbici od koštane jezgre roga, nađeni na lokalitetu Swartkrans u Južnoafričkoj Republici, vjerojatno korišteni za kopanje legla termita, starosti oko 1,8 do 1 milijun godina, koje se vežu za vrstu Australopithecus robustus (Backwell \& d'Errico 2001). Ovo su bili ad hoc upotrijebljeni fragmenti, oblikovani tijekom uporabe. Najstarijim svjesno oblikovanim artefaktima pripadaju oni s lokaliteta Broken Hill u Zambiji, kojima se najvjerojatnije koristio Homo heidelbergensis, starosti oko 300.000 do 140.000 godina (Barham et al. 2002).

Zasad nastarija poznata oruđa od koštanih sirovina u Europi potječu s lokaliteta Schöningen u Njemačkoj, koji je čuven po nalazima drvenih kopalja. U takozvanom „horizontu s kopljima” (spear horizon) pronađeno je i osamdeset osam koštanih artefakata. Uglavnom se radi o dijafizama dugih kostiju, pretežno konja, i manjem broju rebara, koji su korišteni kao obrađivači za oštrenje i popravljanje kremenog oruđa. Pored toga, epifize metapodijalnih kostiju konja i bizona korištene su kao perkuteri, da se slome kosti koje sadrže koštanu srž, a pojedini od ovih „metapodijalnih čekića” iskorišteni su i za okresivanje, što ih čini vjerojatno najranijim višefunkcionalnim oruđem (van Kolfshoten et al. 2015).

Kosti modificirane direktnom perkusijom nedavno su identificirane na još nekoliko lokaliteta iz donjega paleolitika kao što su Vertesszöllös u Mađarskoj, Bilzingsleben u Njemačkoj, Castel di Guido i još nekoliko lokaliteta u Italiji (Rosell et al. 2011: 125-126). Uglavnom se radi o kostima životinja Proboscidea, i ova su oruđa morfološki nalik onim kamenim. Na Bliskom istoku, točnije na lokalitetu Revadim u Izraelu, također su otkriveni predmeti od kostiju slona koji oblikom donekle podsjećaju na ašelejenska kamena oruđa (Rabinovich et al. 2012).

Uporaba kostiju za retuširanje i popravke kremenog oruđa bila je osobito rasprostranjena tijekom paleolitika. Korišteni su fragmenti dugih kostiju, falange, zubi ili fragmenti roga, uglavnom iz otpada, mada se primjećuje i povremeno pažljivije biranje komada koji će se koristiti, pa čak i manja priprema komada kosti prije uporabe (struganje površine i slično). Javljaju se već od donjega paleolitika (Moigne et al. 2015) i poznati su s velikog broja nalazišta u Europi, na 
Bliskome istoku iz prijelaza donjega u srednji paleolitik i iz srednjega paleolitika, kao što su: u Španjolskoj, lokaliteti Gran Dolina (Rosell et al. 2011), pećina Bolomor (Blasco et al. 2013), Cueva Morin (Mozota Holgueras 2012: 276 ff.) i Axlor (Mozota Holgueras 2009), u Francuskoj, lokaliteti La Quina (Malerba \& Giacobini 2002), Terra Amata i Orgnac 3 (Moigne et al. 2015), pećine Noisetier (Mallye et al. 2012), Isturitz (Schwab 2002), u Italiji pećine Fumane (Jéquier et al. 2013) i Riparo Tagliente (Leonardi 1979), potom lokaliteti Vindija i Veternica u Hrvatskoj (Karavanić \& Šokec 2003), Kůlna u Češkoj (Auguste 2002), Kozarnika (Козарника) u Bugarskoj (Guadelli et al. 2013), pećina Qesem u Izraelu (Blasco et al. 2013) i mnogi drugi (PatouMathis ed. 2002) (sl. 1).

Tijekom srednjega paleolitika, od kostiju se, osim obrađivača (retušera), izrađuju i oruđa korištena u druge svrhe kao što su glačalice s lokaliteta Axlor u Španjolskoj (Mozota 2007) i spatule-glačalice (lissoirs), s lokaliteta Pech-de-l’Azé i Abri Peyrony u Francuskoj (Soressi et al. 2013). Osim toga, koštani predmeti još su prepoznati na lokalitetu Salzgitter-Lebenstedt u Njemačkoj - koštani šiljci, zašiljena, zaravnjena i raskoljena rebra i rogovi s tragovima obrade, ukupno preko dvadeset artefakata (Gaudzinski 1998; 1999).

SI. 1: Fragmenti kostiju iskorišteni kao retušeri. Srednji paleolitik, Riparo Tagliente (prema: Leonardi 1979).
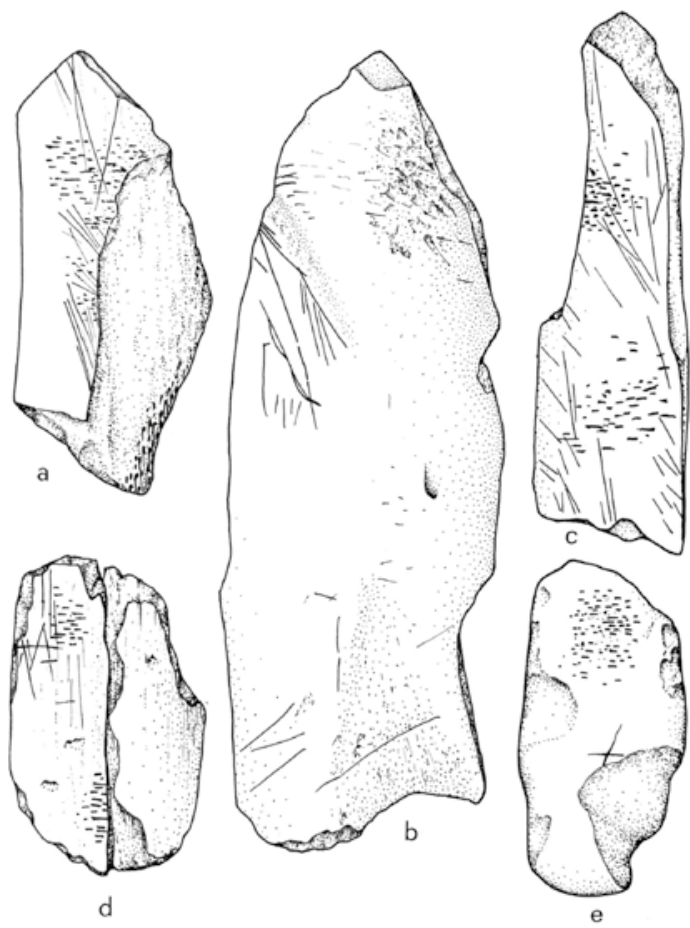

Od gornjega paleolitika uporaba koštanih sirovina postaje osobito rasprostranjena. Sada se javljaju i formalne koštane industrije sa specifičnim tehnološkim i tipološkim odlikama (Arndt \& Newcomer 1986). Tipološki repertoar je veoma raznolik; zastupljeno je oružje kao što su harpuni i projektili, kao i oruđa, korištena u različite svrhe poput obrađivača, glačalica, strugača, igala itd. (Averbouh 2000; Patou-Mathis ed. 2002; Évora 2007). Pored toga, primijećujemo i uporabu ovih sirovina za ukras i za umjetničke predmete (Hahn 1972). Probušeni zubi i razne ljušture školjki i pužića nalaze se na brojnim lokalitetima gornjega paleolitika, i možemo uočiti da su neki prevalili dug put od mjesta gdje je sirovina prikupljena do mjesta gdje su ušli u arheološki zapis (Taborin 2004).

Razne kosti, osobito bjelokost mamuta, također se koriste za izradu reljefnih prikaza i za izradu figurica. Neke od najpoznatijih paleolitičkih figurica izrađene su od mamutove bjelokosti. Tu pripadaju brojne antropomorfne figurice poput Venera iz Lespuguea, Brassempouya, Gagarina (Гагарино), Avdejeva (Авдеево) i drugih lokaliteta (Hahn 1972; Iakovleva 2013) ili zoomorfne 


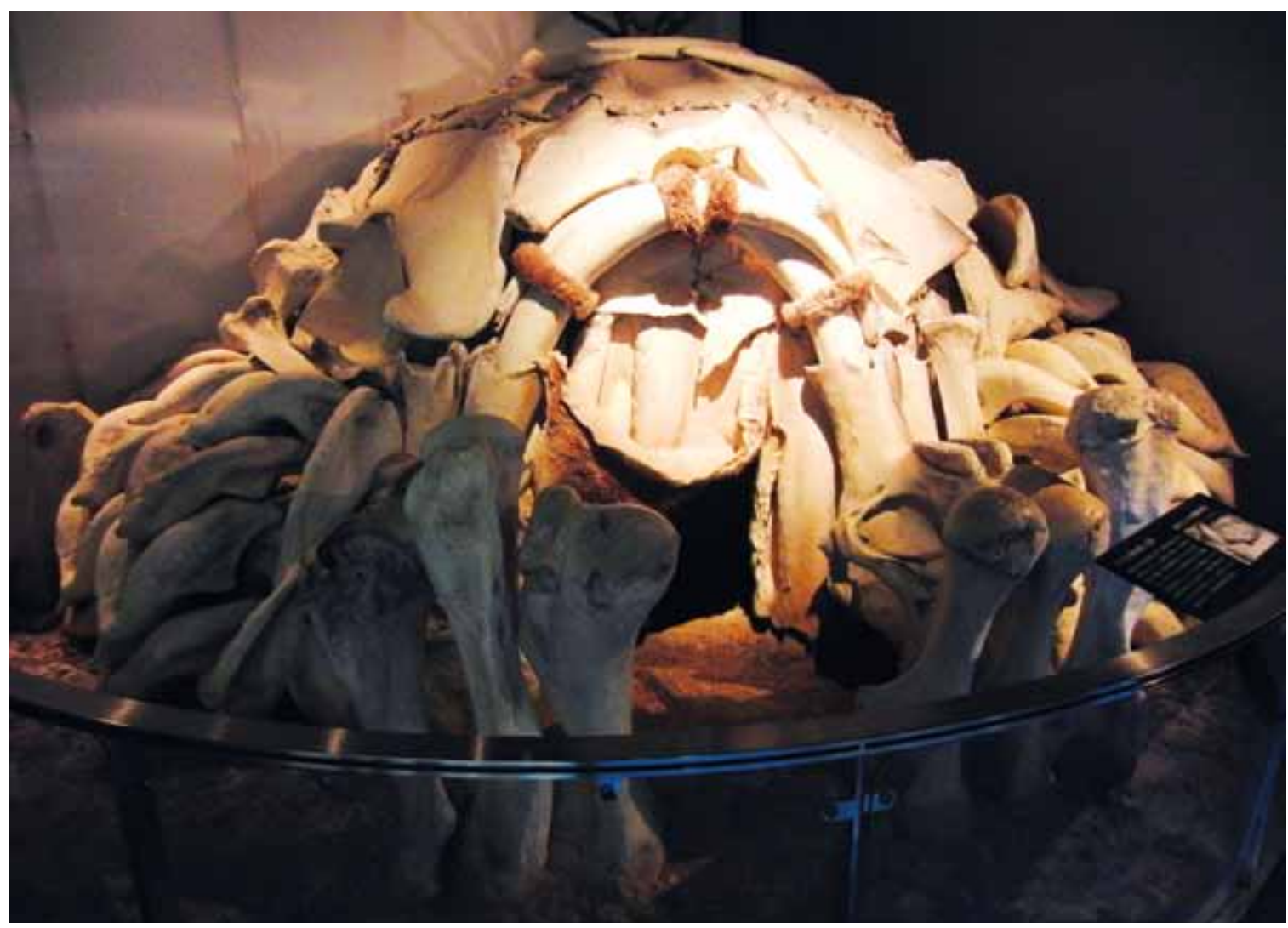

figurice iz Vogelherda (Hahn 1972) i Hohle Felsa (Conrad 2003). Figurica polučovjeka-polulava, Löwenmensch iz pećine Hohlenstein Stade, izrađena je od komada kljove vunastog mamuta dugačkog gotovo $30 \mathrm{~cm}$ (Conrad 2003). Na kraju, rani poznati muzički instrumenti izrađivani su od kostiju, najčešće od dugih kostiju sisavaca ili ptica, a ponekad i od falangi krupnih životinja (Buisson 1990).

Kosti su tijekom posljednjega ledenog doba korištene na još jedan način: za izradu staništa. Naime, kosti mamuta, koje su bile široko dostupne na području koje su pokrivale lovačko-skupljačke grupe, i uz to su bile masivne i povećih dimenzija, korištene su za izradu konstrukcija, koje su potom pokrivane kožama. Takve su konstrukcije pronađene na većem broju lokaliteta koji pripadaju istočnom gravetijenu i epigraveijenu: Dolní Vestonice, Milovice i Pavlov u današnjoj Češkoj, potom Gagarino, Kostienki, Timonovka 1 i 2, Mezine, Suponevo, Boujanka 2 i drugi u današnjoj Ukrajini (Iakovleva 2015; Iakovleva \& Djindjian 2015). Usprkos pojedinačnim specfičnostima, ova staništa imaju sličnu strukturu - kružnog su ili ovalnog oblika, promjera obično 4-6 m, i sazidane su od najvoluminoznijih i najtežih skeletnih elemenata kao što su lopatice, zdjelične kosti i kljove. S lokaliteta Kostienki 11/1a potječu osobito velike strukture; jedna od njih ima čak $9 \mathrm{~m}$ u promjeru i sastojala se od preko 570 kostiju od 40 individua (Iakovleva 2015: 325-326) (sl. 2).

Osim toga, tijekom paleolitika zabilježeno je i korištenje životinjskih kostiju za gorivo, točnije, kao dodatak drvima radi boljeg održavanja vatre i temperature u vatrištima (Théry-Parisot 2002; Théry-Parisot et al. 2005). 
I u kasnijim prapovijesnim razdobljima, kada se postupno uvode novi materijali i nove tehnologije (prerada gline, odnosno keramička tehnologija, metalurgija itd.), kosti, rogovi, zubi i ljušture mekušaca koriste se za alatke, ukrase, neutilitarne predmete i drugo. Koštane industrije postaju više formalne i izbor sirovina je u većoj mjeri planiran, točnije, kosti se sustavno odvajaju za dalju uporabu već tijekom rasijecanja životinje (e. g., Vitezović \& Bulatović 2013). Izrađuju se i dalje razna oruđa, šila, igle, glačalice, strugala, dlijeta, potom dijelovi kompozitnog oruđa, posebno dršci, kao i razni pomoćni predmeti, od kojih su neki široko rasprostranjeni u neizmijenjenom obliku širom Europe, dok pojedini imaju i kronološko-regionalne odlike (Bačkalov 1979; Vitezović 2011; Schibler 2013; Dekker 2014).

Imamo i primjere duge uporabe pojedinih predmeta i njihove česte popravke, prepravke i recikliranja, odnosno primjere kako se od slomljenog ili nefunkcionalnog predmeta pravi novi. Jedan od posebno zanimljivih primjera jesu žlice-spatule od metapodijalnih kostiju goveda, karakteristične za rani neolitik Anadolije i jugoistočne Europe (Dekker 2014; Vitezović 2016b) (sl. 3). Radi se o predmetima u izradu kojih su uloženi poseban trud, vještina i vrijeme, prema eksperimentalnim podacima, oko 25 sati za svaki predmet (Sidéra 2013). Prvobitna namjena ovih predmeta nije jasna jer je velik dio promijenio namjenu i način korištenja tijekom svojega životnog vijeka. Česti su i primjerci koji su ostali u uporabi nakon loma, a od slomljenih držaka izrađivani su projektili i probojci (Vitezović 2016b, s referencama).

Ljušture školjki i pužića i dalje su omiljena sirovina za ukrasne predmete. Predmeti izrađeni od morskih školjki kao što su Spondylus, Glycymeris, Cardium nalaženi su duboko unutar kontinentalne Europe (Borrello 2004; Séfériadès 2010; Ifantidis \& Nikolaidou 2011). Osobito za razdoblje neolitika i eneolitika karakterističan je fenomen trgovine i razmjene Spondylus školjki. Ukrasi od Spondylusa, perle, narukvice, amuleti, privjesci, nalaženi su na brojnim loka-

SI. 3: Žlica-spatula od kosti, s tragovima loma i prepravke. Neolitik, Starčevo-Grad (prema: Vitezović 2011).
SI. 4: Kombinirani perkuter od roga jelena, prepravljen više puta. Rani neolitik, Divostin (prema: Vitezović 2011).
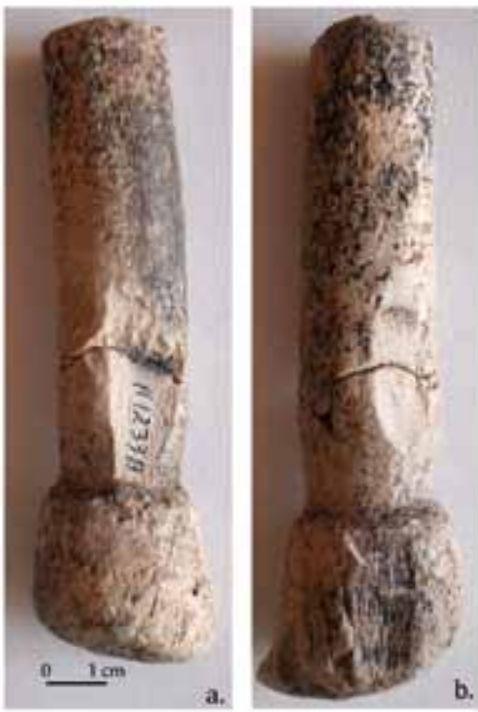

c. 
litetima i u različitim kontekstima, u naseljima i na nekropolama (Séfériadès 2010; Ifantidis \& Nikolaidou 2011). Sami predmeti također su reciklirani - slomljene narukvice pretvarane su u privjeske itd. Štoviše, tijekom eneolitika, broj predmeta se povećava, ali se smanjuju njihove dimenzije (Siklósi \& Csengeri 2011) što također ukazuje na pojačano recikliranje i engl. re-sizing.

Osim morskih, korištene su i slatkovodne školjke, kao što su Unio, koje su prikupljane lokalno i to u prvome redu za prehranu te su potom ljušture, kao kuhinjski otpad, naknadno iskorištene za izradu ukrasnih predmeta. Nalazimo ih na brojnim neolitičkim i eneolitičkim lokalitetima u Europi, na primjer, eneolitički lokalitet Harşova u Rumunjskoj (Mărgărit 2008).

Rogovi jelena i srndaća također su široko korišteni tijekom neolitika, eneolitika i kasnijih razdoblja (Schibler 2013; Vitezović 2014) (sl. 4, 5). Uglavnom se radi o prikupljenim odbačenim rogovima, a količina ukazuje na planirano, sustavno prikupljanje (Vitezović 2014). Štoviše, tafonomski tragovi koji se ponekad mogu uočiti na rogovima, pokazuju da su prikupljeni nakon što su dulje vremena stajali izloženi u prirodi (sl. 5).

SI. 5: Alatka od roga s tragovima glodara, koji pokazuju da je rog prikupljen nakon što je neko vrijeme ležao na otvorenom. Eneolitik, Bubanj-Novo Selo (prema: Vitezović 2016a).

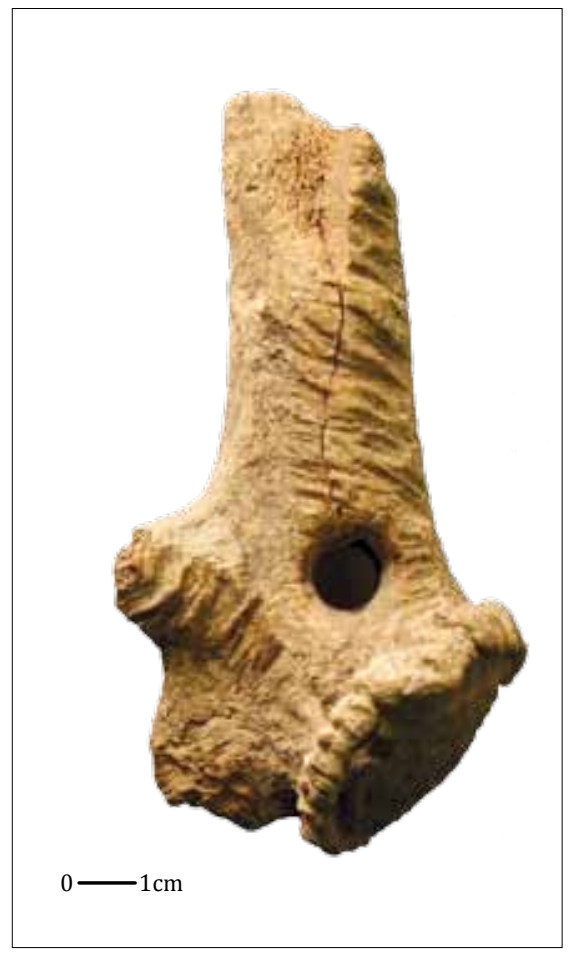

SI. 6: Ukrasni predmeti od školjki i imitacije urađene u kamenu. Brončano doba, Ostojićevo (prema: Vitezović 2017).

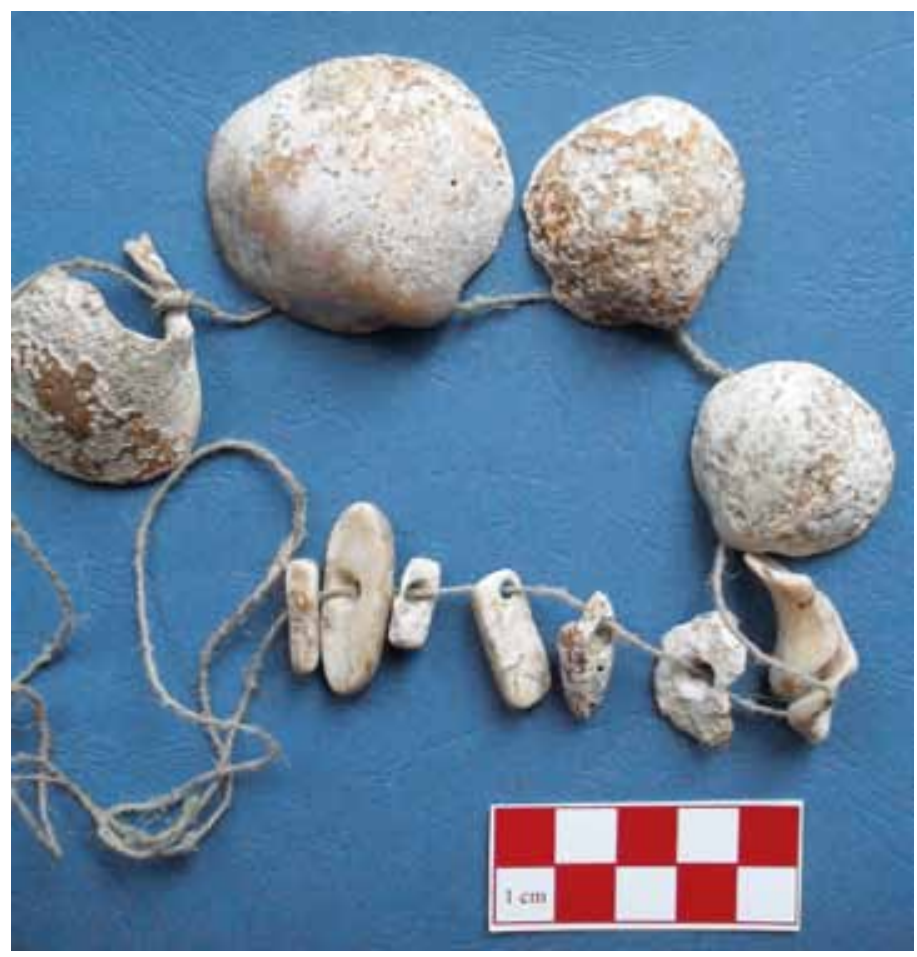

Tijekom brončanoga doba, u pojedinim regijama, kao što je Panonska nizina, rogovi jelena bili su posebno važna i široko rasprostranjena sirovina, korištena za masivna oruđa (čekiće, dlijeta, sjekire itd.), za konjsku opremu i nakit (Choyke 2005). Na primjer, na ranobrončanodobnom lokalitetu Zók u današnjoj Mađarskoj otkrivena je veća količina kako predmeta od baznih dijelova roga tako i prikupljenih rogova s minimalnim tragovima obrade, koji predstavljaju skladištene sirovine i otpatke od proizvodnje (Vitezović \& Mitrović 2016). 
Koštane sirovine koriste se i za izradu osobnog nakita. Na nekropolama moriške kulture Ostojićevo i Mokrin, blizu Kikinde, otkrivena je veća količina nakita od koštanih sirovina, nošenog usporedno s nakitom od metala i kamena (Girić 1971; Vitezović 2017). Radi se o perlama od dugih kostiju, iglama od dugih kostiju, raznim aplikacijama od kosti i roga, probušenim zubima, osobito psa, kao i različitim školjkama i pužićima s perforacijama. Probušeni zubi i školjke osobito su interesantni sa stajališta reciklaže i ponovne uporabe. Naime, u pojedinim se grobovima može uočiti da su tragovi korištenja na pojedinačnim zubima različitog intenziteta, od minimalno iskorištenih do onih na kojima se perforacija toliko izlizala da je pukla i bilo je potrebno napraviti novu. To pokazuje da se nakit od ovih zuba (ogrlica ili narukvica) pravio tijekom duljeg vremena, odnosno povremeno su dodavani novi dijelovi, a moguće je da su neki od njih čak nasljeđivani. Školjkice također pokazuju visok intenzitet iskorištenosti i neke najvjerojatnije predstavljaju fosilne primjerke (Vitezović 2017) (sl. 6).

Tijekom prapovijesti kosti su se još koristile i za izradu boja, osobito bijele boje za oslikavanje keramike i drugih predmeta. Također, školjke su se koristile i za dobivanje pigmenata (Reese 1987; Alberti 2008), ali su povremeno dodavane i u snjesu namijenjenu izradi keramičkih posuda (Rowlett \& Shaw 2005).

\section{Povijesna razdoblja}

Tijekom antike i srednjega vijeka i dalje susrećemo sitna oruđa, pomoćne predmete i osobne ukrase od kostiju - šila, igle, glačalice, drške, vretena i pršljenke, ukrasne igle, kopče, češljeve (MacGregor 1985; Kokabi et al. eds. 1996; Riddler ed. 2003). Javljaju se i novi predmeti kao što su stilusi za pisanje, kockice za igru, kao i vrlo lijepo izrađeni predmeti poput držaka noževa s figuralnim prikazima (Kovač 2017).

U rimskome razdoblju, ukosnice i kozmetičke spatulice izrađene od kostiju posebno su brojne i široko rasprostranjene. Izrađuju se pretežno od kostiju goveda i konja dobivenih iz klaonica. U tome možemo primijetiti povezanost različitih obrtnika koji su iskorištavali otpatke jedne vrste proizvodnje za obradu u drugim. Također, mada je kost bila razmjerno vrlo dostupna, česti su primjeri da su slomljeni predmeti i otpaci reciklirani i prepravljani (Bíró 2003).

Češljevi, čest nalaz na brojnim srednjovjekovnim nalazištima, lako su se lomili, i primjeri popravaka i promjene namjene susreću se u raznim vidovima. Na srednjovjekovnim lokalitetima u Estoniji nađeni su, osim popravljenih, i slomljeni češljevi pretvoreni u privjeske, dvojni češljevi koji su nakon loma pretvoreni u žetone za igru i drugo (Luik 2008) (sl. 7).

Osim toga, kosti, bjelokost, rogovi koriste se i za izradu dekoracija na kovčezima i drugom namještaju, često vrlo umjetnički izrađenih figuralnih prikaza (Bianchi, 2000). Iz povijesnih razdoblja imamo i sigurne podatke o korištenju koštanih sirovina i za izradu predmeta poput lutaka. Kao vrlo interesantna i rasprostranjena pojava mogu se, recimo, izdvojiti lutke iz predislamskog razdoblja, nađene u većem broju na raznim bliskoistočnim lokalitetima (Shatil 2016).

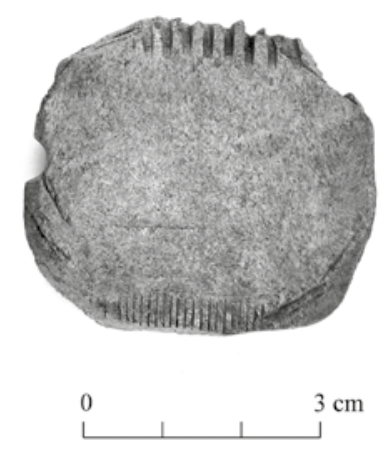

Primjeri korištenja koštanih sirovina kao građevinskog materijala ili kao dodatak građevinskom materijalu poznati su i iz povijesnih razdoblja (Law 2014, s referencama).

SI. 7: Češalj koji je nakon loma pretvoren u žeton za igru. Srednji vijek, Viljandi (prema: Luik 2008). 
S većom raznovrsnošću materijala koja se javlja s industrijalizacijom, značaj koštanih sirovina opada i koriste se uglavnom kao jeftina zamjena za druge, skuplje materijale. U tom smislu je percepcija koštanih sirovina kao otpada značajna - više su cijenjeni materijali koji su egzotični, kao što su bjelokost ili ljušture školjki, i već time se njihovo „otpadno” podrijetlo manje primijećuje ili je više udaljeno.

Iz predmodernih vremena imamo i bolje podatke o korištenju više vrsta koštanih materijala; osim skupocjene bjelokosti, skeletnih elemenata kitova i drugih, egzotičnih sirovina, sad imamo i arheološki očuvane primjerke uporabe keratinastih materijala kao što su rogovi bovida, pa čak i keratinasti dijelovi kopita i papaka (Rijkelijkhuizen 2009; 2010; 2013).

Kosti se i dalje obrađuju u sitni kućanski pribor poput šila i igala potom za ukrasne igle i slično, a koriste se još i za drške, oplate, dijelove kompozitnih predmeta i drugo (Kokabi et al. eds. 1996). U velikoj su mjeri korištene i za izradu brojanica i za dugmad, o čemu svjedoče brojni nalazi otpada diljem europskih gradova. Nalazi iz ulice Roosikrantsi u današnjem Tallinnu u Estoniji, iz kasnoga srednjeg vijeka ili predmodernoga razdoblja, na primjer, arheološki su pokazatelj žive djelatnosti po kojoj je ulica i dobila ime (Luik \& Maldre 2003). Jedan zanimljiv nalaz potječe s Beogradske tvrđave iz 18. stoljeća (sl. 8). Sastoji se od više od 80 otpadaka od rebara, očito kuhinjski otpad, koji su iskorišteni za brzo pravljenje grube dugmadi, vjerojatno da se hitno pripreme uniforme za vojsku (Bikić \& Vitezović 2016). Sličnih primjera korištenja kostiju kao najjeftinijeg i najdostupnijeg materijala za uvijek velike potrebe vojske ima i iz drugih dijelova svijeta (Klippel \& Price 2007).

Za dobivanje pigmenata se, osim školjki, koriste i kosti, rogovi cervida i bovida, osobito za bijelu i crnu boju (Eastaugh et al. 2004).

Čak i u suvremeno doba, doba plastike i drugih, umjetno dobivenih materijala, kost se koristi za izradu pojedinih predmeta. S jedne strane bjelokost je još uvijek cijenjena, mada je trgovina bjelokosti zabranjena konvencijom Ujedinjenih naroda i novi se predmeti ne izrađuju, barem ne legalno (Cvijović 2004). No, od kosti koja je ispolirana tako da imitira bjelokost izrađuju se luksuzni, neuporabni ili predmeti kojima je namjena više ukrasna nego praktična - noževi za papir, minijature, nakit i drugo. Sedefne školjke koriste se za izradu dugmadi i drugih ukrasnih dijelova odjeće, kao i za nakit.

Danas, kosti se još uvijek koriste u različite svrhe u industriji, u građevinarstvu, i mnogo čemu drugom - kao kompost, gnojivo (Jeng et al. 2007), za dodatak prehrani drugim životinjama, za preradu hrane, za pročišćavanje vode (Medellin-Castillo et al. 2007), za dobivanje pigmenata (Eastaugh et al. 2004), za dobivanje ljepila (Mayer 1991) i u mnoge druge svrhe.

\section{Zaključna razmatranja}

Reciklaža i ponovna uporaba materijala u suvremenom svijetu imaju bitno drukčiji oblik i značenje nego u prapovijesti. Dok je današnja reciklaža povezana s održivom uporabom prirodnih resursa, smanjivanjem otpada i općenito sa zaštitom okoliša, i istovremeno neodvojiva od globalnih ekonomskih i političkih zbivanja, ponovna uporaba i reciklaža u prošlosti bili su povezani kako s ekonomijom (štednja ili nedostatak određenih resursa, štednja energije itd.) tako i s kulturnim odnosom prema određenim sirovinama. Proučavanje načina ponovne uporabe materijala u prošlosti može nam pomoći da bolje shvatimo i našu vlastitu potrošnju i odnos prema pojedinim sirovinama. 

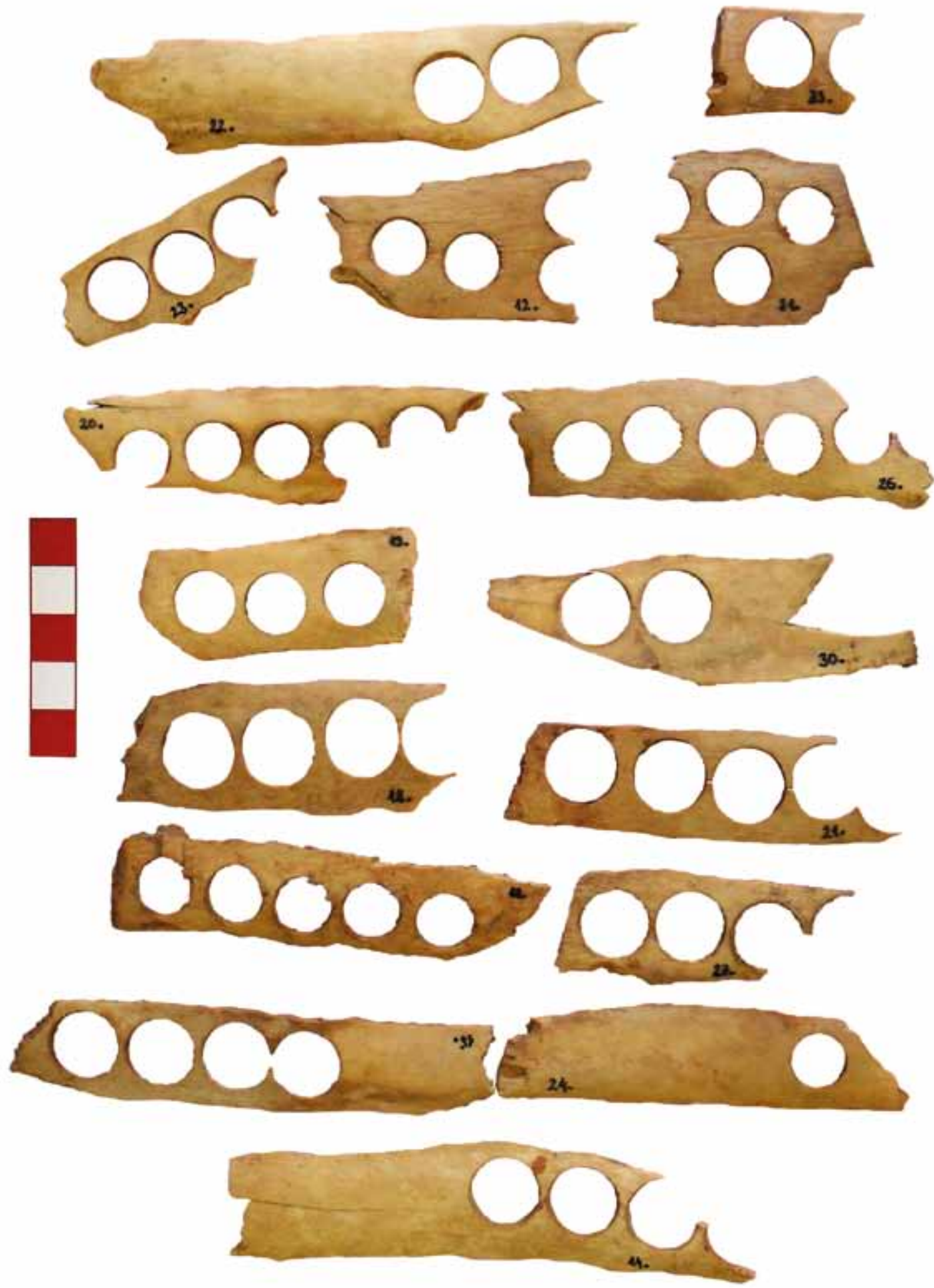

SI. 8: Otpaci od proizvodnje dugmadi. 18. v., Beogradska tvrđava (prema: Bikić \& Vitezović 2016). 


\section{Zahvala}

Zahvalu upućujem Heidi Luik na ustupljenoj ilustraciji.

\section{Literatura}

Al-Bashaireh, K., Al-Mustafa, S., Freestone I. C. \& Al-Housan, A.-Q. 2016. Composition of Byzantine glasses from Umm el-Jimal, northeast Jordan: Insights into glass origins and recycling. Composition of Byzantine glasses from Umm el-Jimal, northeast Jordan: Insights into glass origins and recycling. Journal of Cultural Heritage 21. 809-818. https://doi.org/10.1016/j. culher.2016.04.008

Amick, D. S., 2014. Reflection on the origins of recycling: a paleolithic perspective. Lithic Technology 39 (1). 64-69.

Amick, D. 2015. The recycling of material culture today and during the Paleolithic. Quaternary International 361. 4-20.

Arndt, S. \& Newcomer, M. H. 1986. Breakage patterns on prehistoric bone points. U: Studies in the Upper Palaeolithic of Britain and Northwest Europe. (ur. D. A. Roe). Archaeopress BAR Int. Series 296. Oxford. 165-173.

Auguste, P. 2002. Fiche éclats diaphysaires du Paléolithique moyen Biache-Saint-Vaast (Pas-deCalais) et Kulna (Moravie, Republique Tchèque). U: Retouchoirs, compresseurs, percuteurs... Os à imressions et éraillures. Fiches de la Commission de nomenclature sur l'industrie de l'os préhistorique. Cahier X. (ur. M. Patou-Mathis). CNRS. Paris. 39-58.

Averbouh, A. 2000. Technologie de la matière osseuse travaillée et implications palethnologiques. Thèse de doctorat, Université de Paris I.

Bačkalov, A. 1979. Predmeti od kosti i roga u predneolitu i neolitu Srbije. Savez arheoloških društava Jugoslavije. Beograd.

Backwell, L. \& d'Errico, F. 2001. Evidence of termite foraging by Swartkrans early hominids. Proceedings of the National Academy of Sciences 98/4. 1358-1363.

Barham, L. S., Pinto Llona, A. C. \& Stringer, C. B. 2002. Bone tools from Broken Hill (Kabwe) cave, Zambia, and their evolutionary significance. Before farming 2002/2 (3).

Barkai, R., Lemorini, C., Shimelmitz, R., Lev, Z., Stiner, M.C. \& Gopher, A., 2009. A blade for all seasons? Making and using Amudian blades at Qesem Cave, Israel. Human Evolution 24 (1). 57-75.

Barker, S. J. 2010. Roman builders - pillagers or salvagers?: the economics of deconstruction and reuse. U: Arqueología de la Construcción II: Los processos constructivos en el mundo romano: Italia y provincias occidentales (ur. S. Camporeale, H. Dessales \& A. Pizzo). Anejos de Archivo Español de Aroueología LVII. Madrid-Mérida. 127-142.

Barker, S. J. 2015. Roman stone-carvers and re-carving: ingenuity in recycling. U:

Interdisciplinary Studies on Ancient Stone. ASMOSIA X. Proceedings of the Tenth International Conference of ASMOSIA Association for the Study of Marble \& Other Stones in Antiquity Rome, 2126 May 2012 (ur. E. \& P. Patrizio). Rome. 765-778.

Bianchi, C. 2000. Cremona in età romana. I letti funerari in osso dalla necropoli di S. Lorenzo. Edizioni ET. Milano.

Bikić, V. \& Vitezović, S. 2016. Bone working and the army: an early eighteenth-century button workshop at the Belgrade fortress. U: Close to the bone: current studies in bone technologies (ur. S. Vitezović). Institute of Archaeology. Belgrade. 57-65. 
Bíró, M. 2003. Recycling Worked Bone in Pannonia. Data on the curation of workshop debitage and worn/damaged objects in the Roman bone manufacturing industry. U: Materials of Manufacture. The choice of materials in the working of bone and antler in northern and central Europe during the first millennium $A D$ (ur. I. Riddler). BAR International Series 1193. Oxford. 19-24.

Blasco, R., Rosell J., Cuartero F., Fernández Peris J., Gopher A. \& Barkai R. 2013. Using Bones to Shape Stones: MIS 9 Bone Retouchers at Both Edges of the Mediterranean Sea. PLoS ONE 8, doi:10.1371/journal.pone.0076780.

Borrello, M. 2004. Le conchiglie nella preistoria e nella protostoria. Preistoria Alpina suppl. 1, vol. 40. 19-42.

Buisson, D. 1990. Les flûtes palaéolithiques d'Isturitz (Pyrénées-Atlantiques). Bulletin de la Société préhistorique française 87/10-12. 420-433.

Christensen, M. 2004. Fiches caractères morphologiques, histologiques et mécaniques des matières dures d'origine animale. U: Matières et techniques. Fiches de la Commission de nomenclature sur l'industrie de l'os préhistorique. Cahier XI. (ur. D. Ramseyer). CNRS. Paris. 17-27.

Clutton-Brock, J. 1984. Excavations at Grimes Graves, Norfolk, 1972-1976. Fascicule 1: Neolithic antler picks from Grimes Graves, Norfolk, and Durrington Walls, Wiltshire: a biometrical analysis. London.

Conrad, N. 2003. Palaeolithic Ivory Sculptures from Southwestern Germany and the Origins of Figurative Art. Nature 426 (6968). 830-832.

Cooper, T., 2008. Challenging the 'refuse revolution': war, waste and the rediscovery of recycling, 1900-50. Historical Research 81 (214). 710-731.

Dekker, K. 2014. What tools can tell The Bone Tools of Barcın Höyük. MA thesis. Free University of Amsterdam.

Drackner, M., 2005. What is waste? To whom? - An anthropological perspective on garbage. Waste Management and Research 23 (3). 175-181.

Évora, M. S. 2007. Ustensílagem óssea do paleolítico superior Português. PhD thesis, Universidad do Algarve, Faro.

Gaudzinski, S. 1998. Knochen und Knochengeräte der mittelpaläolithischen Fundstelle Salzgitter-Lebenstedt (Deutschland). Jahrbuch des Römisch-Germanischen Zentralmuseums 45. 163-220.

Gaudzinski, S. 1999. Middle Palaeolithic bone tools from the open-air site Salzgitter-Lebenstedt (Germany). Journal of Archaeological Science 26. 125-141.

Girić, M. 1971. Mokrin: nekropola ranog bronzanog doba. Smithsonian institution, Narodni muzej Kikinda \& Arheološko društvo Jugoslavije. Washington, Kikinda \& Beograd.

Gopher, A., Barkai, R., Shimelmitz, R., Khalaily, M., Lemorini, C., Hershkovitz, I., Stiner, M., 2005. Qesem Cave: an Amudian site in central Israel. Journal of the Israel Prehistoric Society 35. 69-92.

Grünewald, M., Hartmann S. 2015. Überlegungen zum Glasrecycling in der Antike im Bereich des heutigen Deutschland. U: Non solum ... sed etiam. Festschrift für Thomas Fischer zum 65. Geburtstag (ur. P. Henrich, Ch. Miks, J. Obmann \& M. Wieland). Rahden/Westf. 153-164.

Guadelli, A., Fernandez, P., Guadelli, J.-L.: Miteva, V. \& Sirakov, N. 2013. The Retouchers from the Gravettian Levels in Kozarnika Cave. U: The Sound of Bones. Proceedings of the 8th Meeting of the ICAZ Worked Bone Research Group in Salzburg 2011 (ur. F. Lang). Archaeo Plus. Schriften zur Archäologie und Archäometrie der Paris Lodron-Universität Salzburg 5. Salzburg. 155-162.

Hahn, J. 1972. Aurignacian Signs, Pendants and Art Objects in Central and Eastern Europe. World Archaeology 3 (3). 252-266.

Hahn, J. 1986. Kraft und Aggression: die Botschaft der Eiszeitkunst im Aurignacien Süddeutschlands? Archaeologica Venatoria 7. Verlag Archaeologica Venatoria. Institut für Urgeschichte der Universität Tübingen. 
Iakovleva, L. 1999. L’art mézinien en Europe orientale dans son contexte chronologique, culturel et spirituel. L'Anthropologie 113. 691-752.

Iakovleva, L. \& Djindjian, F., 2005. New data on Mammoth bone settlements of Eastern Europe in the light of new excavations of the Gontsy site (Ukraine). Quaternary International 126-128. 195-207.

Ifantidis, F. \& Nikolaidou, M. eds. 2011. Spondylus in prehistory. New data and approaches. BAR International Series S2216. Archaeopress. Oxford.

Jeng, A. S., Haraldsen, T. K., Grønlund, A. \& Pedersen, P. A. 2007. Meat and bone meal as nitrogen and phosphorus fertilizer to cereals and rye grass. U: Advances in Integrated Soil Fertility Management in sub-Saharan Africa: Challenges and Opportunities (ur. A. Bationo, B. Waswa, J. Kihara \& J. Kimetu). Springer. Dordrecht.

Jéquier, C. A., Romandini, M. \& Peresani, M., 2012. Les retouchoirs en matières dures animales: une comparaison entre Moustérien final et Uluzzien. Comptes Rendus Palevol 11. 283-292.

Law, M. 2014. Mollusc Shells from Archaeological Building Materials. U: Archaeomalacology: Shells in the Archaeological Record. Proceedings of the 11th ICAZ International Conference. Paris - Archaeomalacology Working group, 23-28 August 2010 (ur. K. Szabó, C. Dupont, V. Dimitrijević, L. G. V., Gastélum Gómez \& N. Serrand). BAR International Series, 2666. Archaeopress/British Archaeological Reports. Oxford. 253-256.

Leonardi, P. 1979 Una serie di ritoccatoi prevalentemente musteriani del Riparo Tagliente in Valpantena presso Verona. Preistoria Alpina 15. 7-15.

Karavanić, I. \& Šokec, T. 2003. The Middle Paleolithic Percussion or Pressure Flaking Tools? The comparison of experimental and archaeological material from Croatia. Prilozi Instituta za arheologiju u Zagrebu 20. 5-14.

Klippel, W. E. \& Price, B. E. 2007. Bone Disc Manufacturing Debris from Newfoundland to Antigua During the Historic Period. U: Bones as Tools: Current Methods and Interpretations in Worked Bone Studies (ur. Ch. Gates St-Pierre \& R. B. Walker). BAR International Series 1622. Oxford. 133-142.

Kokabi, M., Schlenker, B. \& Wahl, J. ur. 1996. Knochenarbeit - Artefakte aus tierischen Rohstoffen im Wandel der Zeit. Archäologische Informationen aus Baden-Württemberg 27. Stuttgart.

Luik, H. \& Maldre, L. 2003. Luutöötlemisest Tallinna eeslinnas, Roosikrantsi tänava piirkonnas, 13.-17. sajandil. Journal of Estonian Archaeology 7/ 1. 3-37.

Luik, H. 2008. Could broken bone combs have had new lives? Estonian Journal of Archaeology 12, 2. 152-162.

MacGregor, A. 1985. Bone, antler, ivory and horn. The technology of skeletal materials since the Roman period. Croom Helm. London \& Sydney.

Malerba, G. \& Giacobini, G. 2002. Fiche éclats diaphysaires avec marques transversales d'utilisastion. U: Retouchoirs, compresseurs, percuteurs... Os à imressions et éraillures. Fiches de la Commission de nomenclature sur l'industrie de l'os préhistorique. Cahier X. (ur. M. Patou-Mathis). CNRS. Paris. 29-37.

Mallye, J.-B., Thiébaut, C., Mourre, V., Costamagno S., Claud É. \& Weisbecker P. 2012. The Mousterian bone retouchers of Noisetier Cave: experimentation and identification of marks. Journal of Archaeological Science 39. 1131-1142.

Mayer, R. 1991. The Artist's Handbook of Materials and Techniques. Viking. New York.

Mărgărit, M. 2008. Les perles en valves de Unio dans l'habitat énéolithique de Harşova-tell (départment de Constanța). Annales d'Université „Valahia” Târgovişte. Section d'Archéologie et d'Histoire X. 73-77. 
Medellin-Castillo, N. A., Leyva-Ramos, R., Ocampo-Perez, R., Garcia de la Cruz, R. F., AragonPiña, A., Martinez-Rosales, J. M., Guerrero-Coronado, R. M., Fuentes-Rubio, L. 2007. Adsorption of Fluoride from Water Solution on Bone Char. Industrial \& Engineering Chemistry Research 46 (26). 9205-9212.

Moigne, A.-M., Valensi, P., Auguste, P., García-Solano, J., Tuffreau, A., Lamotte, A., Barroso, C. \& Moncel, M.-H. 2015. Bone retouchers from Lower Palaeolithic sites: Terra Amata, Orgnac 3, Cagny-l'Epinette and Cueva del Angel. Quaternary International, http://doi.org/10.1016/j.quaint.2015.06.059

Mozota Holgueras, M. 2007. Los retocadores óseos del Paleolítico Medio, una experimentación para la obtención de soportes. U: Actas del I Congreso Español de Arqueología Experimental (Santander, 24-25 de Noviembre de 2005). Asociación Española de Arqueología Experimental. Santander. 225-233.

Mozota Holgueras, M. 2009. El utillaje óseo musteriense del nivel "D" de Axlor (Dima, Vizcaya. análisis de la cadena operativa. Trabajos de Prehistoria 66. 27-46.

Mozota Holgueras, M. 2012. El hueso como materia prima: el utillaje óseo del final del Musteriense en el sector central del norte de la Península Ibérica. PhD thesis, Universidad de Cantabria.

Patou-Mathis, M. ur. 2002. Retouchoirs, compresseurs, percuteurs... Os à imressions et éraillures. Fiches de la Commission de nomenclature sur l'industrie de l'os préhistorique. Cahier X. CNRS. Paris.

Rabinovich, R., Ackermann, O., Aladjem, E., Barkai, R., Biton, R., Milevski, I., Solodenko, N. \& Marder, 0. 2012. Elephants at the Middle Pleistocene Acheulian open-air site of Revadim Quarry, Israel. Quaternary International 276-277. 183-197.

Reese, D. S. 1987. Palaikastro shells and Bronze Age purple-dye production in the Mediterranean Basin. The Annual of the British School of Archaeology at Athens 82. 201-206.

Reese, D. S. 1991. Marine shells in the Levant: Upper Paleolithic, Epipaleolithic and Neolithic. U: The Natufian Culture in the Levant (ur. O. Bar-Yosef \& F. R. Valla). Archaeological Series 1, International Monographs in Prehistory. Ann Arbor, Michgen. 613-628.

Reitz, E. J. \& Wing, E. S. 2008. Zooarchaeology. Cambridge University Press. Cambridge (2 ${ }^{\text {nd }}$ ed.). Riddler, I. D. ur. 2003. Materials of Manufacture. The choice of materials in the working of bone and antler in northern and central Europe during the first millennium AD. BAR International Series 1193. Oxford.

Rijkelijkhuizen, M. 2013. Horn and hoof - plastics of the past: The use of horn and hoof as raw materials in the Late and Post-Medieval periods in the Netherlands. U: The Sound of Bones. Proceedings of the 8th Meeting of the ICAZ Worked Bone Research Group in Salzburg 2011 (ur. F. Lang). Archaeo Plus. Schriften zur Archäologie und Archäometrie der Paris Lodron-Universität Salzburg 5. Salzburg. 217-226.

Rijkelijkhuizen, M. J. 2009. Whales, Walruses, and Elephants: Artisans in Ivory, Baleen, and Other Skeletal Materials in Seventeenth- and Eighteenth-Century Amsterdam. International Journal of Historical Archaeology 13(4). 409-429.

Rijkelijkhuizen, M. J. 2010. Tortoiseshell in the 17th and 18th Century Dutch Republic U: Ancient and Modern Bone Artefacts from America to Russia. Cultural, technological and functional signature (ur. A. Legrand-Pineau, I. Sidéra, N. Buc, E. David \& V. Scheinsohn). BAR International Series 2136. Archaeopress. Oxford. 97-106.

Rosell, J., Blasco, R., Campeny, G., Díez, C., Alcalde, R. A., Menéndez, L., Arsuaga, J. L., Bermúdez de Castro, J. M. \& Carbonell, E. 2011. Bone as a technological raw material at the Gran Dolina site (Sierra de Atapuerca, Burgos, Spain). Journal of Human Evolution 61. 125-131. 
Schibler, J. 2007. Knochen, Zahn, Geweih und Horn: Werkstoffe der prähistorischen und historischen Epochen. Nova Acta Leopoldina Neue Folge 94. 45-63.

Schibler, J. 2013. Bone and antler artefacts in wetland sites. U: The Oxford handbook of Wetland archaeology (ur. F. Menotti \& A. O'Sullivan). Oxford University Press. Oxford. 339-355.

Schiffer, M. B., 2010. Behavioral Archaeology: Principles and Practice. Equinox. London.

Séfériadès M. L. 2010. Spondylus and long-distance trade in prehistoric Europe. U: The Lost World of Old Europe: The Danube Valley 5000-3500BC. Lost world of europe The Danube Valley 5000-3500BC (ur. D. Anthony). The Institute for the study of the Ancient World \& Princeton University Press. New York, Princeton \& Oxford. 178-190.

Sidéra, I. 2013. Manufacturing bone tools: The Example of Kovačevo. U: Bioarheologija na Balkanu. Bilans i perspektive (ur. N. Miladinović-Radmilović \& S. Vitezović). Radovi bioarheološke sekcije Srpskog arheološkog društva. Beograd-Sremska Mitrovica. 173-178.

Siklósi, Zs. \& Csengeri P. 2011. Reconsideration of Spondylus usage in the Middle and Late Neolithic of the Carpathian Basin. U: Spondylus in prehistory. New data and approaches (ur. F. Ifantidis \& M. Nikolaidou). BAR International Series S2216. Archaeopress. Oxford. 47-62.

Soressi, M., McPherron, S., Lenoir, M., Dogandzic, T., Goldberg, P., Jacobs Z., Maigrot Y., Martisius N. L., Miller C. E., Rendu W., Richards M., Skinner M. M., Steele T. E., Talamo S. \& Texier J.-P. 2013. Neandertals made the first specialized bone tools in Europe. Proceedings of the National Academy of Sciences 110/35. 14186-14190, doi: 10.1073/pnas.1302730110

Taborin, Y. 2004. Langage sans parole. La parure aux temps préhistoriques, La Maison des roches. Paris.

Théry-Parisot, I., Costamagno, S., Brugal, J.P. \& Guilbert, R. 2005. The use of bone as fuel during the Palaeolithic, experimental study of bone combustible properties. U: The Archaeology of Milk and Fats. 9th ICAZ Conferences, Durham 2002 (ur. J. Mulville \& A. Outram). Oxbow. Oxford. 50-59.

Théry-Parisot, I. 2002. Fuel management (bone and wood) during the lower Aurignacian in the Pataud rock shelter (Lower Palaeolithic, Les Eyzies de Tayac, Dordogne, France): contribution of experimentation and anthraco-analysis to the study of the socio-economic behaviour. Journal of Archaeological Science 29. 1415-1421.

Toro-Moyano, I., de Lumley, H., Fajardo, B., Barsky, D., Cauche, D., Celiberti, V., Gregoire, S., Martinez-Navarro, B., Espigares, M. P. \& Ros-Montoya, S., 2009. L'industrie lithique des gisements du Pléistocène infèrieur de Barranco León et Fuente Nueva 3 à Orce, Grenade, Espagne. L'Anthropologie 113 (1). 111-124.

van Kolfshoten, T., Parfitt S. A., Serangeli, J. \& Bello, S. M. 2015. Lower Palaeolithic bone tools from the "Spear Horizon" at Schöningen (Germany). Journal of Human evolution 89. 228-263. DOI: 10.1016/j.jhevol.2015.09.012

Vitezović, S. \& Bulatović, J. 2013. Managing raw materials in Vinča culture: A case study of osseous raw materials from Vitkovo. Documenta praehistorica 40. 279-289.

Vitezović, S. 2011. Koštana industrija u starijem i srednjem neolitu centralnog Balkana. PhD Thesis. Filozofski fakultet. Univerzitet u Beogradu. Beograd.

Vitezović, S. 2014. Antlers as raw material in the Starčevo culture. U: Archaeotechnology: studying technology from prehistory to the Middle Ages (ur. S. Vitezović \& D. Antonović). Srpsko arheološko društvo. Beograd. 151-176.

Vitezović, S. 2016a. Metodologija proučavanja praistorijskih koštanih industrija. Srpsko arheološko društvo. Beograd. 
Vitezović, S. 2016b. Bos and the bone spoon revisited: Spatula-spoons in the Starčevo culture. U: Southeast Europe and Anatolia in prehistory. Essays in honor of Vassil Nikolov on his 65th anniversary (ur. K. Bacvarov \& R. Gleser). Universitätsforschungen zur prähistorischen Archäologie Band 293 Aus der Abteilung für Ur- und Frühgeschichtliche Archäologie der Universität Münster. Verlag Dr. Rudolf Habelt GmbH. Bonn. 189-196.

Vitezović, S. \& Mitrović, J. 2016. Antler technology in the Bronze Age: The case study of Zók. U: 11th Meeting of the Worked Bone Research Group of the ICAZ. Programme and abstracts, Iaşi, Romania, 23-28. May 2016. Iaşi. 38-39.

Vitezović, S. 2017. Jewellery from osseous materials in the Bronze Age in the southern Carpathian Basin. U: First meeting of the UISPP Commission Bone Artefact. 2 \&3 March 2017, University of Trnava, Slovak Republik. 13. 